$3-2000$

\title{
Movement Coupling at the Ankle During the Stance Phase of Running
}

\author{
Alex Stacoff \\ University of Calgary, stacoff@biomech.mat.ethz.ch \\ Benno M. Nigg \\ University of Calgary \\ Christoph Reinschmidt \\ University of Calgary \\ Antonie J. van den Bogert \\ Cleveland State University, a.vandenbogert@csuohio.edu \\ Arne Lundberg \\ University Hospital, Huddinge, Sweden
}

See next page for additional authors

Follow this and additional works at: https://engagedscholarship.csuohio.edu/enme_facpub

Part of the Biomechanical Engineering Commons

How does access to this work benefit you? Let us know!

\section{Original Citation}

Stacoff, A., Nigg, B. M., Reinschmidt, C., 2000, "Movement Coupling at the Ankle during the Stance Phase of Running," Foot \& Ankle International, 21(3) pp. 232-239.

This Article is brought to you for free and open access by the Mechanical Engineering Department at EngagedScholarship@CSU. It has been accepted for inclusion in Mechanical Engineering Faculty Publications by an authorized administrator of EngagedScholarship@CSU. For more information, please contact library.es@csuohio.edu. 


\section{Authors}

Alex Stacoff, Benno M. Nigg, Christoph Reinschmidt, Antonie J. van den Bogert, Arne Lundberg, Edgar Stüssi, and Jachen Denoth 


\title{
Movement Coupling at the Ankle During the Stance Phase of Running
}

\author{
Alex Stacoff Ph.D. ${ }^{1,5}$, Benno M. Nigg Prof. Dr. sc.nat.', Christoph Reinschmidt Ph.D. ${ }^{1,3}$, Anton J. van den Bogert Ph.D. ${ }^{1,4}$, \\ Arne Lundberg M.D., Ph.D. ${ }^{2}$, Edgar Stüssi Prof. Dr. phil.nat. ${ }^{5}$ and Jachen Denoth Dr. sc.nat. ${ }^{5}$ \\ Calgary, Canada', Huddinge, Sweden', Winterthur, Switzerland ${ }^{6}$, Schlieren, Switzerland ${ }^{5}$, Cleveland, Ohio ${ }^{4}$
}

\begin{abstract}
The purpose of this study was to quantify movement coupling at the ankle during the stance phase of running using bone-mounted markers. Intracortical bone pins with reflective marker triads were inserted under standard local anaesthesia into the calcaneus and the tibia of five healthy male subjects. The three-dimensional rotations were determined using a joint coordinate system approach. Movement coupling was observed in all test subjects and occurred in phases with considerable individual differences. Between the shoe and the calcaneus coupling increased after midstance which suggested that the test shoes provided more coupling for inversion than for eversion. Movement coupling between calcaneus and tibia was higher in the first phase (from heel strike to midstance) compared with the second phase (from midstance to take-off). This finding is in contrast to previous in-vitro studies but may be explained by the higher vertical loads of the present in-vivo study. Thus, movement coupling measured at the bone level changed throughout the stance phase of running and was found to be far more complex than a simple mitered joint or universal joint model.
\end{abstract}

\section{INTRODUCTION}

Biomechanical factors which have been associated with the development of running injuries at the ankle,

\footnotetext{
'Human Performance Laboratory, The University of Calgary, Canada; ${ }^{2}$ Karolinska Institute, Dept. . of Orthopaedics, University Hospital, Huddinge, Sweden; ${ }^{3}$ Sulzer Orthopedics Ltd., Winterthur, Switzerland; ${ }^{4}$ Biomedical Engineering, Lerner Research Institute, Cleveland Clinic Foundation, Cleveland, USA; ${ }^{5}$ Laboratory for Biomechanics, ETH Zürich, Schlieren, Switzerland

Please send correspondence to:

Alex Stacoff

Laboratory for Biomechanics

Dept.. of Materials, ETH Zürich

Wagistrasse 4

8952 Schlieren

Switzerland

Phone: ++4116336211

Fax: ++4116331124

E-mail: Stacoff@biomech.mat.ethz.ch
}

shank, and knee include excessive foot eversion and excessive tibial rotation. ${ }^{2.14,22}$ The etiology of these injuries is presently not well understood. ${ }^{21,22,25}$ It has been suggested, that excessive tibial rotation may be the result of excessive foot eversion transferred through a coupling mechanism at the ankle. ${ }^{2,13,14,19,36}$ Thus, movement coupling at the ankle may be related with various running injuries. Furthermore, there is evidence, that this coupling mechanism is increased in high-arched and stiff feet. ${ }^{26}$

Movement coupling at the ankle has been discussed for many decades. Coupling between foot eversion and internal tibial rotation has been associated with the oblique orientation of the subtalar joint axis. $4,6,9,10,12,13,15,23$ Movement coupling during walking was first investigated by Levens et al. ${ }^{18}$ and by Wright et al. ${ }^{37}$ who concluded that the tibial rotation must be resolved at the subtalar joint. Later, Lundberg ${ }^{19}$, using implanted markers invivo, found that moving the foot from pronation to supination induced some vertical axis rotation of the lower leg, indicating the existence of a rotation transferring mechanism. The work of Levens and co-workers ${ }^{18}$ quantifying tibial rotation using bone pins started a series of in-vivo investigations aimed at the understanding of skin and shoe marker artefacts that may mask the kinematics of the underlying bone. ${ }^{1,16,20,28,29}$ Up to the present, most studies on kinematics of running have used externally mounted skin and shoe markers which have been demonstrated to overestimate skeletal movements ${ }^{28,29}$ and thus do not represent the movements of the underlying bones. Therefore, the knowledge of tibiocalcaneal movement coupling during running is limited at the present time.

Movement coupling between foot inversion/eversion and tibial rotation has also been described by in-vitro studies. ${ }^{11,13,17,27,31}$ The coupling was found to be higher between inversion and external tibial rotation than between eversion and internal tibial rotation and was found to depend on vertical load, plantar/dorsiflexion, ligament integrity and muscle-tendon forces.

Movement coupling at the ankle occurs between the shoe and the foot as well as between the foot and the 
shank. In-vivo, movement coupling between foot/shoe and shank has been described by Nigg et al. ${ }^{26}$ and McClay et al. ${ }^{21}$ using external markers during running. The coupling between shoe eversion and calcaneus eversion was first described by Reinschmidt et al. $^{28}$ using bone pins in running.

The purpose of this study was to provide basic information to describe and quantify the movement coupling between (i) shoe and calcaneus and the (ii) calcaneus and tibia during the stance phase of running.

\section{METHODS}

\section{General Project Description}

The experiments were performed in the Department of Orthopaedics, Karolinska Institute at Huddinge University Hospital, Stockholm. Ethical approval for the experiments was obtained from the Ethics committees of the Karolinska Hospital and The University of Calgary. The experimental set-up, test procedure, data analysis and data reduction have been described previously in detail. $28,29,33,34$

In brief, five healthy male volunteers, all injury free with no previous injury history that might influence their locomotion patterns, participated as test subjects (28.6 \pm 4.3 yrs., mass $83.4 \pm 10.2 \mathrm{~kg}$ and height $185.1 \pm 4.5$ $\mathrm{cm}$ ). Bone pins (size: $2.5 \mathrm{~mm}$ external fixator pin, miniHofman) with reflective marker triads (size of markers: $10 \mathrm{~mm}$ diameter) were inserted under standard local anesthetic (Citanest $10 \mathrm{mg} / \mathrm{ml}$ ) which was active for 2-3 hours, leaving enough time for the experiments (Figure 1). The pins were inserted at the tibia (anterior lateral aspect of tibial condyle) and calcaneus (posterior lateral aspect). The subjects gave their informed consent to participate in the study and performed three heel-toe running trials with a speed of between 2.5 to $3.0 \mathrm{~m} / \mathrm{s}$ (Figure 2). Trials were repeated if the subjects did not land with their right foot on the force plate and/or if they made an obvious gait pattern modification in order to hit the force plate.

The tests were performed with a running shoe (Adidas Equipment Cushioning) with a rearfoot shoe sole modification (straight shoe sole, Shore A45). This sole modification was regarded as a neutral shoe sole design with no extremes of lateral heel flare or midsole hardness ${ }^{34}$ The test shoes had a cutout at the lateral heel counter to avoid impingement with the calcaneal bone pin. ${ }^{33,34}$ The shoe markers were placed at the posterior lateral aspect of the heel counter, at the dorsum of the foot (lateral cuneiform), and at the lateral tuberosity of the fifth metatarsal (Figure 1). Three high-speed cine cameras (LOCAM) were placed around a force platform (KISTLER) mounted flush to the runway. The camera

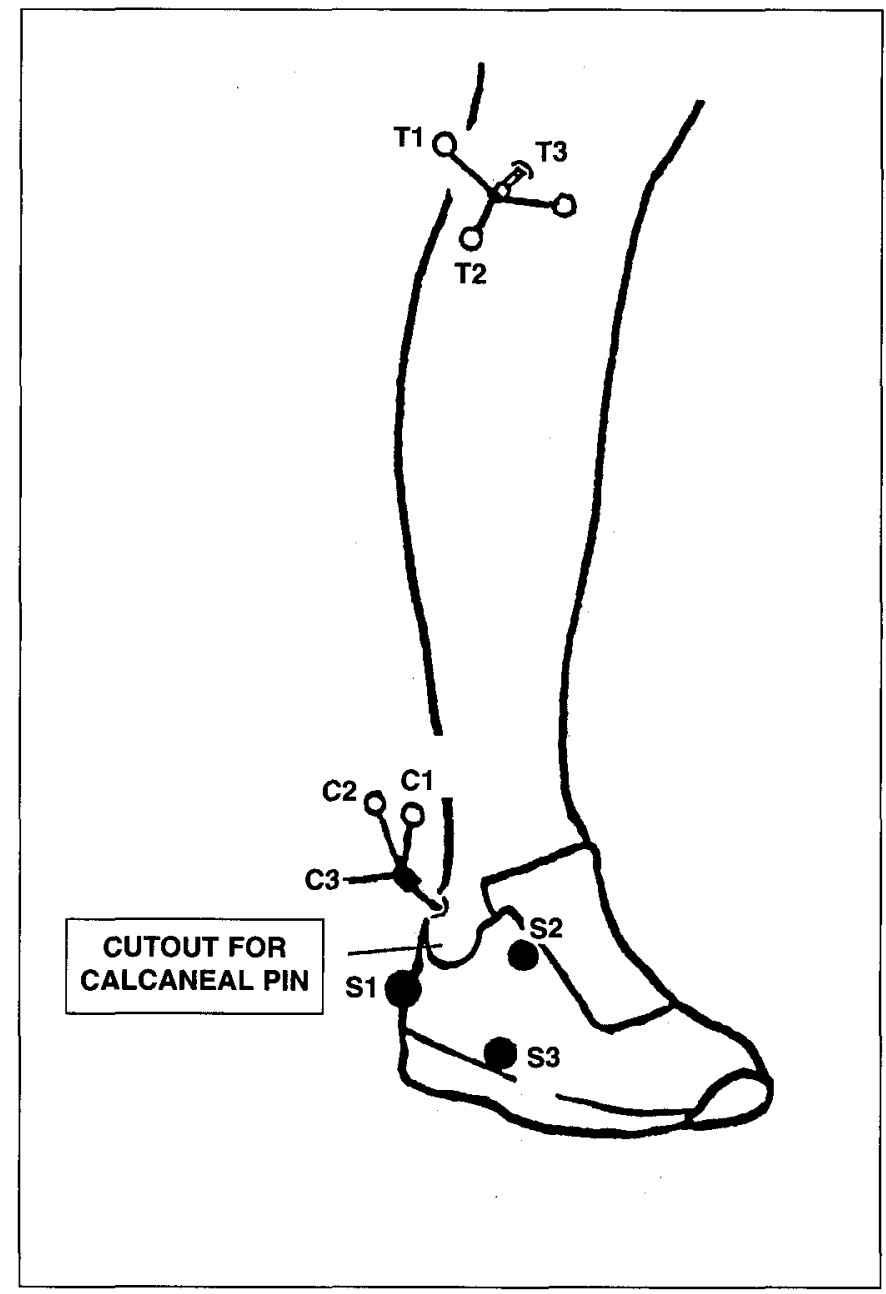

Fig. 1 Positioning of markers attached to the bone pins and shoe: tibia markers (T1 to T3), calcaneus markers ( $\mathrm{C} 1$ to $\mathrm{C} 3$ ), and shoe markers (S1 to S3)

speed was set at $200 \mathrm{~Hz}$ and three LED's, triggered by a threshold detector connected to the force plate, were used to synchronize the cameras. A calibration frame with 6 control points $\left(0.5 \times 0.5 \times 0.5 \mathrm{~m}^{3}\right)$ was used for the three-dimensional data reconstruction.

\section{Data Analysis of Tibiocalcanal Rotations}

KineMat, a set of programs written in MATLAB ${ }^{\mathrm{TM}}$, was adapted from Reinschmidt and van den Boger ${ }^{30}$ for the specific needs of this investigation. The programs served to reconstruct the three-dimensional marker positions and to calculate the relative segmental movements. The barefoot standing trial was used as the neutral position to define the segment-fixed calcaneus and tibia coordinate systems. The standing trial with the shoe was used for the shoe marker analysis. The rotations between the segments were calculated as Cardanic angles for the stance phase of all test conditions using a joint coordinate system (JCS) ${ }^{8}$. The 


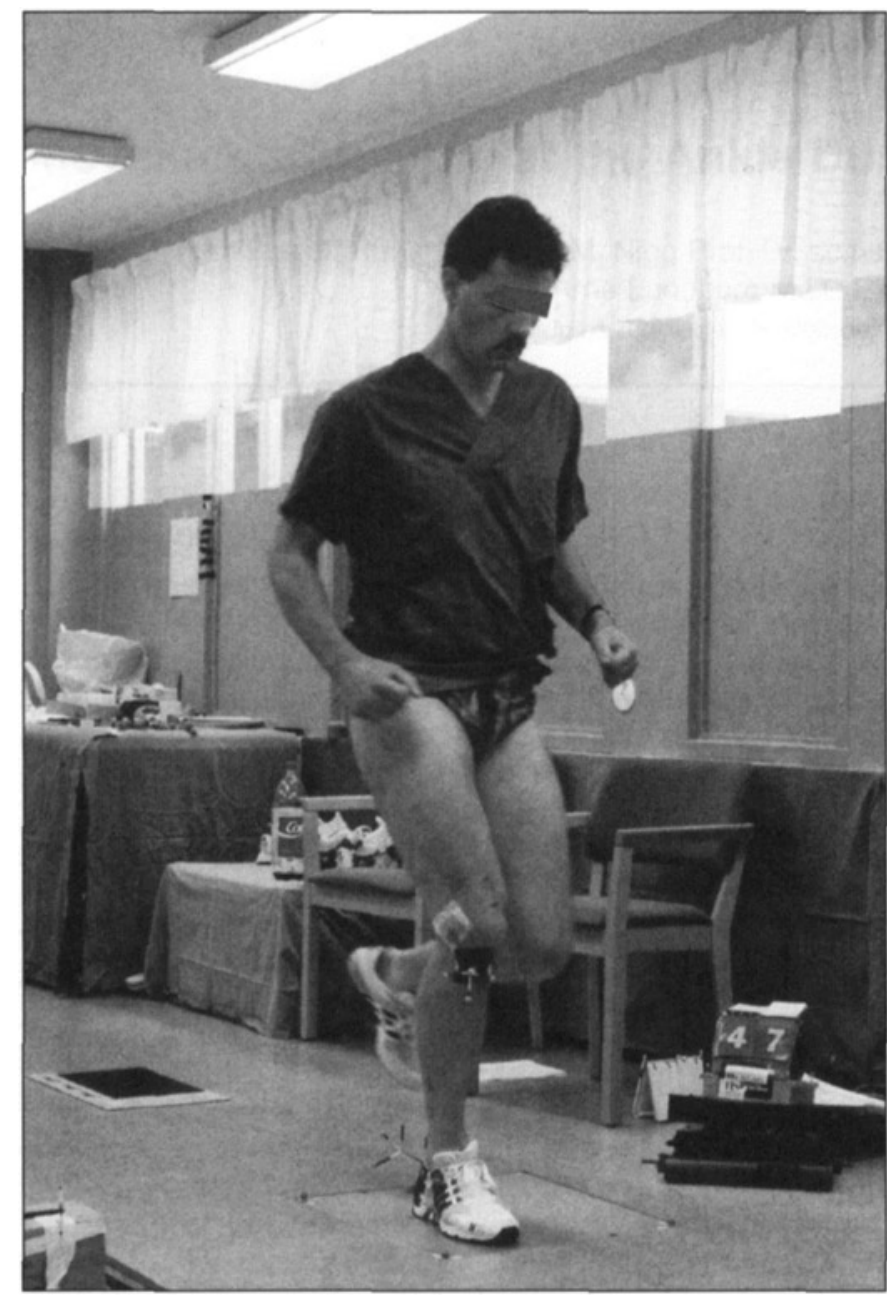

Fig. 2 Heel-toe running of subject during testing with inserted bone pins.

defined sequence of rotations at the ankle joint complex was plantar/dorsiflexion about a tibia fixed medio-lateral axis, foot ab/adduction about the floating axis, and inversion/eversion about the antero-posterior axis of the foot. ${ }^{3}$ Tibial rotation was calculated using the sequence: tibial rotation about a tibia fixed proximal-distal axis, inversion/eversion about the floating axis, and plantar/dorsiflexion about a calcaneus fixed medio-lateral axis. ${ }^{26}$

The accuracy of the spatial reconstruction between two marker triads was determined (i) based on the residuals of the DLT equations averaged over the entire stance phase for all markers and (ii) based on the deviations of the inter-marker distances of the same trials. The mean error based on DLT residuals was found to be in the order of $\pm 4^{\circ}$ which included noise error and lens distortion error. The mean error based on marker distances (RMS) was found to be $\pm 1.0^{\circ}$ including noise error only. Thus, for the present study, a realistic estimation of the error was likely to be between the two errors given above. The error of the shoe data was about $\pm 1.0^{\circ}$ higher than that at the bone, because it included inaccuracies of different standing trials with different shoes.

\section{Definitions of Variables}

The variables used in this study are summarized and defined in Tables 1 and 2. Total eversion is equivalent to the range of motion in eversion of the calcaneus relative to the tibia between touchdown and maximum, based on bone marker measurements. Analogous definitions to those in Table 1 were used for the shoe markers and the skeletal markers at the tibia. Thus, total shoe eversion was defined as $\Delta \beta_{\text {maxsnoe, }}$, and total internal tibial rotation (tibia relative to calcaneus) as $\Delta \rho_{\max }$. These definitions follow the nomenclature of previous investigations on the kinematics of running. ${ }^{16,25,29}$

Movement coupling describes how much movement occurs about one axis of rotation relative to a simultaneous rotation about a second axis. Thus, in mechanical terms, movement coupling describes the gear ratio between two segments. When applying this concept to the ankle, the two axes of rotation are the calcaneus fixed eversion/inversion axis and tibia fixed external/internal rotation axis. The "mitered joint model" by Inman ${ }^{13}$ shows an unchanged coupling between the shank and the foot. Consequently, the coupling of such a model is "rigid". The coupling of the human ankle joint, however, is dependent on various factors (as described above 11,13.17,27,31), and is likely to be "non-rigid".

The coupling coefficient was defined as the ratio of the total rotation about one axis over the total rotation about a second axis (Table 2). This coefficient has been used in previous in-vitro investigation s $^{11,19,27}$ as well as invivo studies ${ }^{21,26}$. In general, the magnitude of the coupling coefficient is subject and joint specific. A high coupling coefficient indicates that most of the rotation of one segment can also be observed on the other; thus, the gear ratio would be large (close to or larger than 1). A small coefficient would indicate that less movement of one segment was transferred to the next and the gear ratio would become small (close to 0 ). The coefficient may have some potential to characterize different types of feet which needs to be verified in future work. Some evidence has been provided by Nigg et al. ${ }^{26}$ who showed that movement coupling is increased in higharched and stiff feet.

The stance phase in running can be divided in a loading phase (heel strike to midstance) and a propulsion phase, or (in short) unloading phase (midstance to takeoff). In-vitro studies ${ }^{11,12,27,31}$ have shown that movement coupling may not be identical in these two phases. Thus, the coefficients of Table 2 (defined for the loading phase) were computed also for the unloading phase. 
For this purpose the take-off variables $\beta_{\text {то }}$, and $\rho_{\text {то }}$ were used. Total inversion was then defined as $\Delta \beta_{\max } \beta_{\text {Tо }}$ and in analogy to that the variables of the tibia. Thus, the coupling coefficients were computed for the loading phase and the unloading phase respectively. The coupling results of this study were illustrated with angleangle diagrams.

\section{RESULTS}

\section{Coupling Coefficients and Repeatability of Test Movements}

The results of three running trials of one subject are presented in Figure 3. Generally, the shape of the curves showing movement coupling between shoe and calcaneus and between calcaneus and tibia were found to be very similar. Eversion and internal tibial rotation took place between heel strike and midstance, thereafter the movements were reversed to inversion and external tibial rotation. These general movement patterns were found to be consistent for all test subjects.

Most coupling coefficients (Table 3 ) were consistent within each condition, illustrated by the small standard deviation, but varied considerably between segments and between subjects.

\section{Coupling between Shoe and Calcaneus}

Movement coupling between shoe and calcaneus showed two distinct phases during the ground contact of running (Figure 4). From heel strike to midstance the shoe and the calcaneus moved into (shoe/calcaneus) eversion, from midstance to take-off into (shoe/calcaneus) inversion. Coupling differed considerably between the subjects. During the loading phase shoe eversion was about twice that of calcaneal eversion for subjects 1,3 and 5 , with the coupling coefficient being around 0.5 (Table 3). The coupling coefficient for subjects 2 and 4 was between 0.7 and 0.8 . The average coupling coefficient for the loading phase was 0.61 and was increased by $34 \%$ in the unloading phase $(0.83)$. Total shoe eversion relative to the tibia was between $12^{\circ}$ (subject 5) and $23^{\circ}$ (subject 1; Figure 4). The other three subjects showed values between these two extremes.

\section{Coupling between Calcaneus and Tibia}

Movement coupling from the calcaneus to the tibia generally showed curves similar to shoe-calcaneus movement coupling. From heel strike to midstance the calcaneus everted and the tibia rotated internally, from midstance to take-off the calcaneus inverted and the tibia rotated externally. However, with respect to magnitude and individual patterns of the curves the five subjects showed considerable differences (Figure 5).

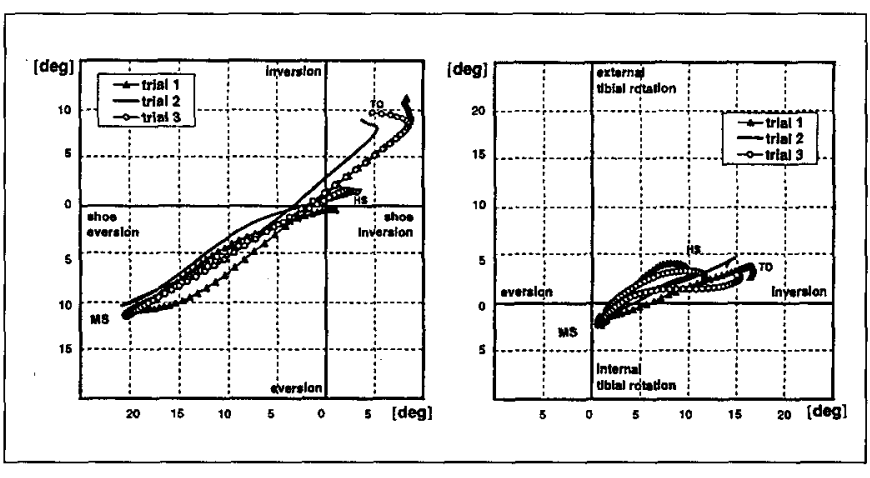

Fig. 3 Three running trials of subject 1 illustrating the repeatability of the testing procedure. Movement coupling is presented between shoe and calcaneus (left) and between calcaneus and tibia (right). Subject 1, straight shoe; HS (heel strike); MS (midstance); TO (takeoff)

During the loading and unloading phase the coupling coefficients between calcaneus and tibia ranged between 0.24 (subject 2) to 0.96 (subject 5; Table 3). The coupling coefficients decreased in the unloading phase compared to the loading phase for all subjects, except subject 5 where it remained unchanged. Further it can be observed that the coupling coefficient between calcaneus and tibia was smaller than between the shoe and calcaneus for all subjects but one (subject 5). Total calcaneal eversion relative to the tibia was found between $6^{\circ}$ (subject 5) and $11^{\circ}$ (subjects 1 and 2) and total internal tibial rotation relative to the foot was found between $3^{\circ}$ (subject 3 ) and $6^{\circ}$ (subject 4; Figure 5).

\section{DISCUSSION}

\section{Coupling between Shoe and Calcaneus}

The coupling between shoe and calcaneus showed two distinct phases, one from heel strike to midstance, and one from midstance to take-off with an increase in coupling (i.e. a larger gear ratio) in the second half (Figure 4). Additionally, the first phase might be divided in two sub-phases, because immediately after touchdown shoe eversion increased more than that of the calcaneus in all but subject 5 . Thus, during landing the shoe and the calcaneus were found with lower coupling coefficients in four of the five subjects. It may be argued that at touchdown lower coupling coefficients are welcomed, because higher coefficients would increase eversion of the calcaneus which could enhance the risk of injury. On the other hand, a good fit inside the shoe may offer better control and decrease relative movements between the calcaneus and the shoe (see subject 4 with a very rigid coupling). However, at the present time it is not known which is the better solution.

During the second half of the first phase coupling 
increased in all subjects (except subject 4 , who already had a high coupling) compared to the first half. When attempting to reduce excessive eversion of the calcaneus, a high shoe-calcaneus coupling coefficient seems advantageous (in the second half), provided the shoe has the capacity to reduce eversion. One such shoe construction which has often be attributed to reduce eversion is the heel counter. ${ }^{32}$ However, van Gheluwe et al. ${ }^{7}$ reported that with rigid heel counters more relative movement between the shoe and the foot should be expected, and that a rigid heel counter would decrease shoe-calcaneus coupling. Hence, the effect of heel counters on calcaneus movement may have to be reviewed using the shoe-calcaneus coupling coefficient as a possible indicator. Furthermore, the large subject differences in shoe-calcaneus coupling of the present study indicated that coupling between the shoe and calcaneus is subject dependent.

From midstance to take-off all subjects showed a high shoe-calcaneus coupling coefficient and the differences between the subjects became smaller. During this phase high coupling may be advantageous in order to reduce relative movements of the foot inside the shoe. It is suggested, that relative movements (i.e. slipping inside the shoe) would be a disadvantage during the propulsion phase of running.

It may be argued that shoe eversion/inversion was overestimated in this study, since two shoe markers were set at the dorsum of the foot recording midfoot eversion rather than pure heel eversion. It has been estimated that this marker setting increased maximum eversion by about 2-4 degrees compared to shoe markers set at the heel only. ${ }^{34}$ Thus, the present shoe inversion/eversion results may be dependent on the position of the shoe markers, a problem which may have to be investigated systematically in future studies.

\section{Coupling between Calcaneus and Tibia}

Coupling between calcaneus and tibia changed in all subjects throughout the stance phase of running. This finding is in contrast to the "mitered joint" or "universal joint" model, which has been used to visualize the coupling between the foot and shank. ${ }^{12,13}$ The present study confirms previous in-vitro and in-vivo studies that the ankle joint complex does generally not work like a universal joint. $5,11,17,24,27,31$

The present study showed that the coupling coefficients between eversion and internal tibial rotation were higher than between inversion and external tibial rotation. This is in contrast to the results of the in-vitro study of Hintermann ${ }^{11}$, with low eversion-internal tibial rotation coupling and high inversion-external tibial rotation coupling. Vertical loading was identified as one factor which increased eversion of the foot (up to $600 \mathrm{~N}$ load) in

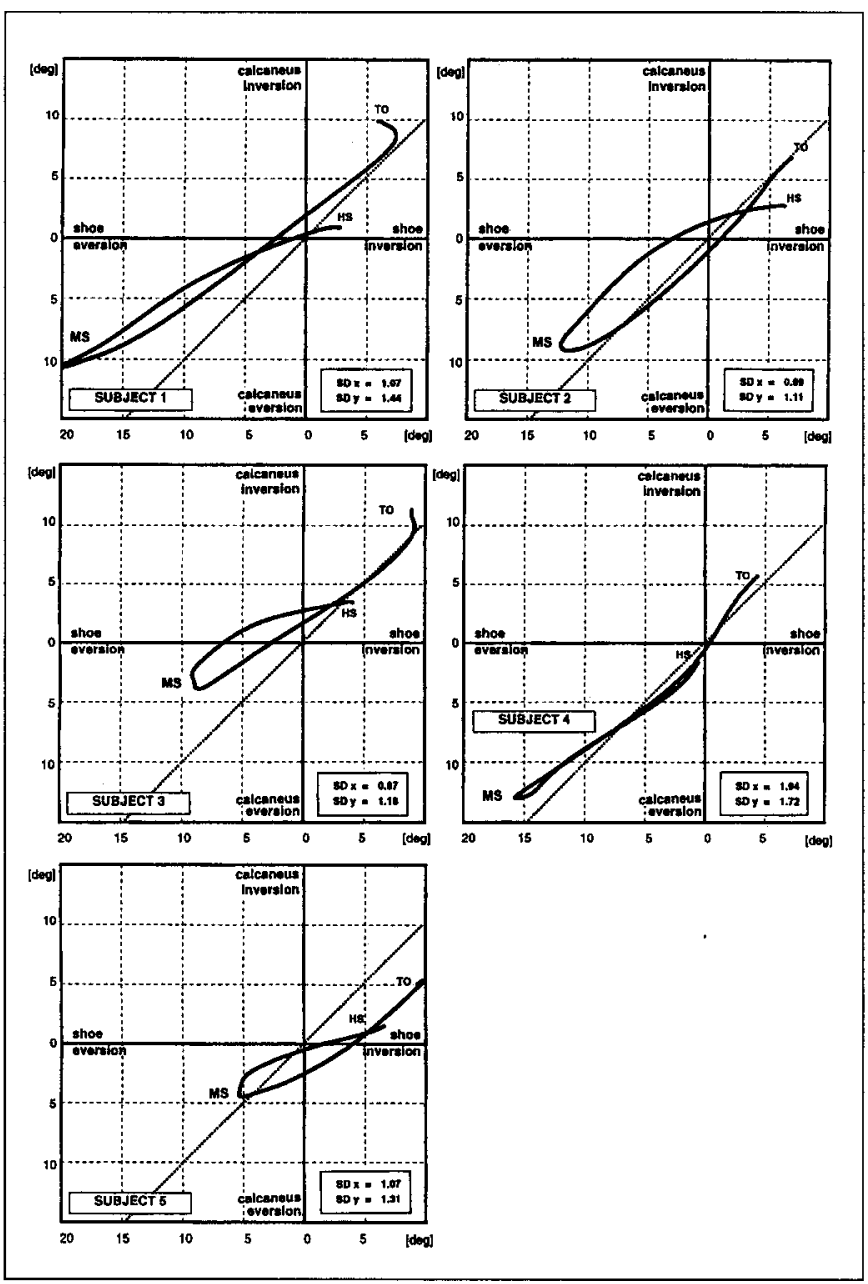

Fig. 4 Movement coupling between shoe eversion-inversion and calcaneal eversion-inversion for the five test subjects (mean curves of three repetitions). The dashed line represents a theoretical $1: 1$ coupling from the shoe to the calcaneus.HS (heel strike); MS (midstance); TO (takeoff); SD [mean standard deviation in the horizontal $(\mathrm{x})$ and vertical (y) direction]

Hintermann's"1 study. That load was considerably less than in the present study, where the vertical loads were expected to be between 1500 and $2000 \mathrm{~N}$. Thus, it is possible that the low eversion-internal tibial rotation coupling of Hintermann's study" may have been due to comparatively low vertical loading and that the coupling results of the present study are due to the higher vertical loads applied in-vivo.

Engsberg et al. ${ }^{5}$ (1987) concluded that although eversion is the major rotational component, ab/adduction or plantar/dorsiflexion may contribute to the coupling mechanisms at the ankle. Furthermore, there may also be more proximal inputs (thigh and hip) to rotations at the tibia. Thus, future studies should analyze movement coupling at the ankle joint complex with a $3 D$ input and a 3D output.

Tibiocalcaneal motion during running has been meas- 


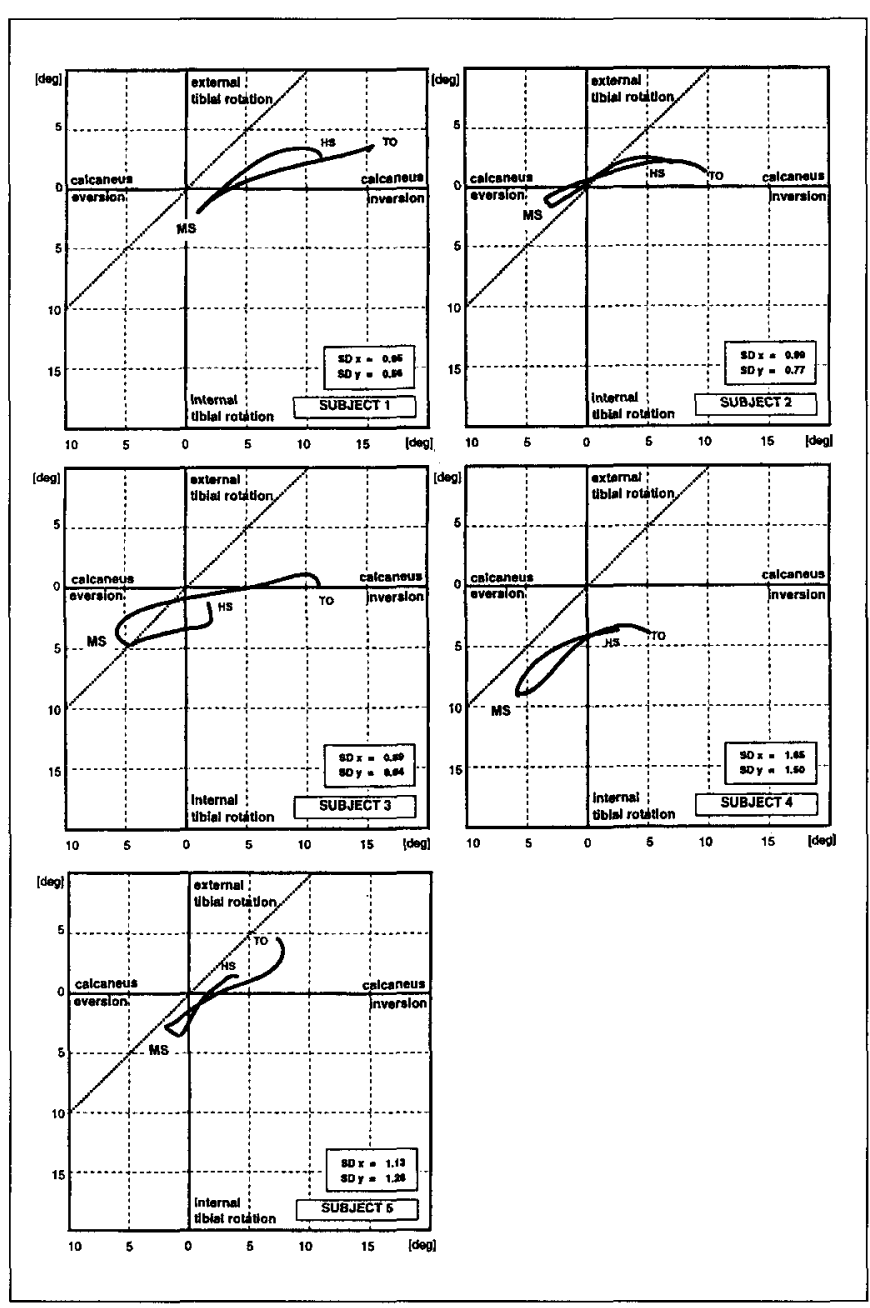

Fig. 5 Movement coupling between calcaneal eversion-inversion and tibial rotation for the five test subjects (mean curves of three repetitions). The dashed line represents a theoretical 1:1 coupling from the calcaneus to the tibia. HS (heel strike); MS (midstance); TO (takeoff); SD (mean standard deviation in the horizontal $(x)$ and vertical (y) direction)

ured and reported using skin and shoe mounted markers. $^{21,26}$ Values from these studies corresponded well with the present study. The small discrepancies between previous studies and the present one may be the result of overestimation due to external marker settings. ${ }^{21,26}$

The above discussed results may have been influenced by the application of local anaesthesia and by the special construction of the test shoes:

- Local anaesthesia was necessary because of the invasive character of the study. In order to test a possible anesthetic effect a pilot study was conducted (with the same test subjects) ${ }^{29}$ in which the pre-and postoperative ankle joint rotations were found to be similar, the maximum differences being $2^{\circ}$ only. Thus, the movement pattern of running may be difficult to alter even with the insertion of bone pins and the use of local anesthesia.

- The cutout in the lateral heel counter (Figure 1) was necessary to prevent impingement with the calcaneal bone pin. This cutout may have reduced heel counter rigidity and the fit of the foot inside the shoe and thus may have changed movement coupling between the calcaneus and the shoe. On the other hand, van Gheluwe et al. ${ }^{7}$ reported that with rigid heel counters more relative movement (shoe-calcaneus) should be expected, and that a rigid heel counter would decrease shoe-calcaneal coupling. Whether or not heel counter rigidity or lateral cutouts had systematic effects during testing cannot be answered conclusively.

\section{SUMMARY AND CONCLUSION}

The present in-vivo study related to movement coupling in the lower extremity during the stance phase of slow running $(2.5 \mathrm{~m} / \mathrm{s}$ to $3.0 \mathrm{~m} / \mathrm{s})$ showed the following findings:

- Movement coupling was observed from the shoe to the calcaneus and from the calcaneus to the tibia. In all subjects coupling was found to take place in distinct phases, but with considerable individual differences.

- Coupling between the shoe and the calcaneus increased from the loading to the unloading phase which suggested that the test shoes provided more coupling for inversion than for eversion. It was further suggested that future studies may use shoe-calcaneus coupling as an indicator to test the effects of shoe interventions.

- Coupling between the calcaneus and the tibia decreased from the loading phase to the unloading phase of running. This finding is in contrast to previous in-vitro studies but may be explained by the higher vertical loads of this investigation. The present study confirmed that ankle joint coupling with the calcaneus and tibia is far more complex than a mitered or universal joint. It was suggested that future studies may use calcaneus-tibia coupling to describe different foot types during running.

\section{REFERENCES}

1. Capozzo, A., Catani, F., Leardini, A., Benedetti, M.G., and Della Croce, U.: Position and orientation in space of bones during movement: experimental artefacts. Clinical Biomechanics, 11:90-100, 1996.

2. Clement, D.B., Taunton, J.E., Smart, G.W., and McNicol, K.L.: A survey of overuse running injuries. The Physician and Sports Medicine, 9:47-58, 1981.

3. Cole, G.K., Nigg, B.M., Ronsky, J.L., and Yeadon, M.R.: Application of the joint coordinate system to three-dimensional joint attitude and movement representation: a standardization proposal. 
TABLE 1

DEFINITIONS OF BONE MARKER VARIABLES

(Analogous definitions were used for the shoe markers and the skeletal markers at the tibia)

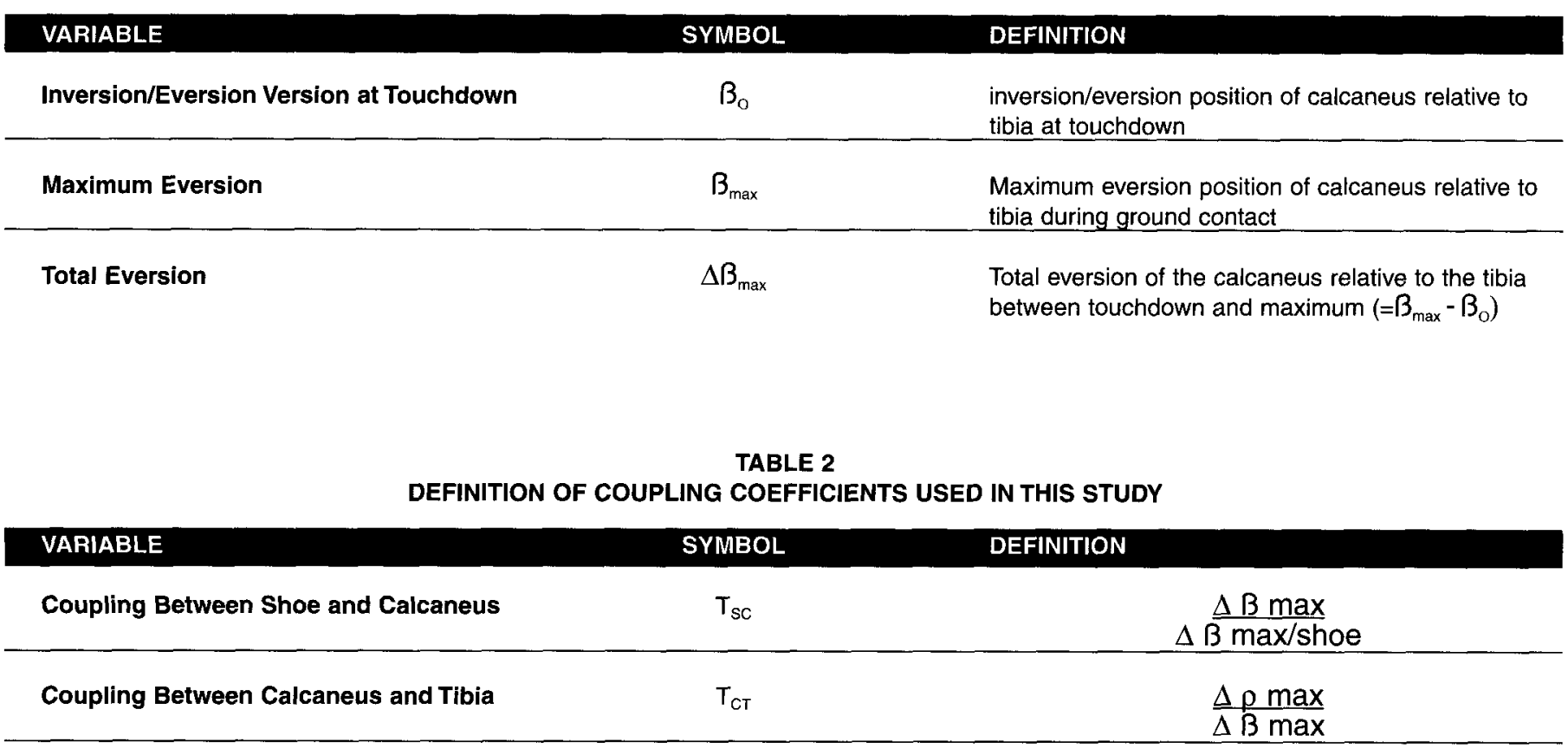

TABLE 3

COUPLING COEFFICIENTS FROM SHOE TO CALCANEUS (TSC) AND FROM THE CALCANEUS TO THE TIBIA (TCT) FOR THE LOADING AND UNLOADING PHASE

\begin{tabular}{|c|c|c|c|c|c|c|c|}
\hline Phase & Coefficient & Subject 1 & Subject 2 & Subject 3 & Subject 4 & Subject 5 & Mean \\
\hline \multirow[t]{2}{*}{ Loading } & $\mathbf{T}_{s c}$ & $0.52 \pm 0.03$ & $0.68 \pm 0.02$ & $0.57 \pm 0.11$ & $0.80 \pm 0.15$ & $0.49 \pm 0.12$ & $0.61 \pm 0.13$ \\
\hline & $T_{\text {cr }}$ & $0.47 \pm 0.07$ & $0.35 \pm 0.03$ & $0.43 \pm 0.15$ & $0.68 \pm 0.26$ & $0.96 \pm 0.51$ & $0.58 \pm 0.24$ \\
\hline \multirow[t]{2}{*}{ Unloading } & $\mathbf{T}_{s c}$ & $0.80 \pm 0.02$ & $0.86 \pm 0.03$ & $0.86 \pm 0.06$ & $0.98 \pm 0.09$ & $0.66 \pm 0.07$ & $0.83 \pm 0.11$ \\
\hline & $\mathbf{T}_{\mathrm{CT}}$ & $0.36 \pm 0.02$ & $0.24 \pm 0.03$ & $0.29 \pm 0.05$ & $0.45 \pm 0.11$ & $0.95 \pm 0.35$ & $0.46 \pm 0.29$ \\
\hline
\end{tabular}

Journal of Biomechanical Engineering, 115:344-349, 1993.

4. Elftman, H., and Manter, J.: The evolution of the human foot, with special reference to the joints. Journal of Anatomy, London, 70:5667, 1935.

5. Engsberg, J.R., and Andrews, J.G.: Kinematic analysis of the talocalcaneal/talocrural joint during running support. Medicine and Science in Sports an Exercise, 19:275-284, 1987.

6. Fick, R.: Ueber die Arbeitsleistung der auf die Fussgelenke wirkenden Muskeln. Universitätsdruckerei, Würzburg, 1911.

7. Gheluwe, B. Van, Tielemans, R., and Roosen, P.: The influence of heel counter rigidity on rearfoot motion during running. Journal of Applied Biomechanics, 11:47-67, 1995.

8. Grood, E.S., and Suntay, W.J.: A joint coordinate system for the clinical description of three-dimensional motions: application to the knee. Journal of Biomechanical Engineering, 105:136-144, 1983.

9. Henke, W.: Die Bewegung des Fusses am Sprungbein. Zeitschrift Ratgeber Medizin, 7:225-234, 1859.

10. Hicks, J.H.: The mechanics of the foot, I. The Joints. Journal of
Anatomy, 87:345-357, 1953.

11. Hintermann, B.: Die mechanische Kopplung der Sprunggelenke. [The mechanical coupling of the ankle joints]. Habilitationsschrift der Universität Basel, 1994.

12. Inman, V.T.: The influence of the foot-ankle complex on the proximal skeletal structures. Artificial Limbs, 13:59-65, 1969.

13. Inman, V.T.: The joints of the ankle. Williams and Wilkins, Baltimore, 1976.

14. James, S.L., Bates, B.T., and Osternig, L.R.: Injuries to runners. American Journal of Sports Medicine, 6:40-50, 1978.

15. Jones, R.: The functional significance of the declination of the axis of the subtalar joint. Anatomical Records, 151-159, 1945.

16. Lafortune, M.A., Cavanagh, P.R., Sommer III, H.J., and Kalenak, A.: Foot-inversion-eversion and knee kinematics during walking. Journal of Orthopaedic Research, 12:412-420, 1994.

17. Langelaan van, E.J.: A kinematical analysis of the tarsal joints. Acta Orthopaedica Scandinavica, Supplementum, 204:54, 1983.

18. Levens, A.S., Inman, V.T., and Blosser, J.A.: Transverse rotation 
of the segments of the lower extremity in locomotion. Journal of Bone and Joint Surgery [Am], 30:859-872, 1948.

19. Lundberg, A.: Kinematics of the ankle and foot: in vivo roentgen stereophotogrammetry. Acta Orthop. Scand., 60, Suppl. 233:1-26, 1989.

20. McClay, I.S.: A comparison of tibiofemoral and patellofemoral joint motion in runners with and without patellofemoral pain. Unpublished PhD thesis of The Pennsylvania State University, USA, 1990.

21. McClay, I.S, Manal, K.: Coupling parameters in runners with normal and excessive pronation. Journal of Applied Biomechanics, 13:109-124, 1997.

22. Mechelen, W. van: Running injuries: a review of the epidemiological literature. Sports Medicine, 14:320-335, 1992.

23. Meyer, H.: Die Individualität des aufrechten Ganges [The individuality of upright gait], Müller's Archiv, 548-573, 1853.

24. Murphy, N.: Ankle and subtalar joint three-dimensional kinematics obtained with the helical axis model and estimated from talus, calcaneus and foot markers. Thése, Université de Montréal, 1993.

25. Nigg, B.M., Bahlsen, A.H., Denoth, J., Lüthi, S., and Stacoff, A.: Factors influencing kinetic and kinematic variables in running. In: Biomechanics of running shoes, Human Kinetics, Champaign, Illinois, B.M. Nigg, 1986, p. 139-160.

26. Nigg, B.M, Cole, G.K., and Nachbauer, W.: Effects of arch height of the foot on angular motion of the lower extremities in running. Journal of Biomechanics, 26:909-916, 1993.

27. Olerud, C., and Rosendahl, Y.: Torsion-transmitting properties of the hind foot. Clinical Orthopaedics and Related Research, 214:285-294, 1985.

28. Reinschmidt, C., van den Bogert, A.J., Murphy, N., Lundberg, A., Nigg, B.M.: Tibiocalcaneal motion during running, measured with external and bone markers. Clinical Biomechanics; 12:8-16, 1997 a.

29. Reinschmidt, C., van den Bogert, A.J., Lundberg, A., Murphy, N., Nigg, B.M., Stacoff, A., and Stano, A.: Tibiofemoral and tibiocalcaneal motion during walking: external vs. skeletal markers. Gait and Posture, 6:98-109, 1997b.

30. Siegler, S., Chen, J., and Schneck, C.D.: The three-dimensional kinematics and flexibility characteristics of the human ankle and subtalar joints - part l: Kinematics. Journal of Biomechanical Engineering, 110:364-372, 1988.

31. Stacoff, A., Reinschmidt, C., Stüssi, E.: The movement of the heel within a running shoe. Medicine and Science in Sports and Exercise, 24:695-701, 1992.

32. Stacoff, A., Reinschmidt, C., Nigg, B.M., van den Bogert, A.J., Lundberg, A., Denoth, J., Stüssi, E.: Effects of shoe sole construction on skeletal motion during running. Accepted for publication in Medicine and Science in Sports and Exercise, 1998b.

33. Stergiou, P.: Biomechanical factors associated with patellofemoral pain syndrome in runners. Unpublished Master Thesis. The University of Calgary, Alberta, Canada.

34. Wright, D.G., Desai, M.E., and Henderson, B.S.: Action of the subtalar and ankle joint complex during the stance phase of walking. Journal of Bone and Joint Surgery, 46-A:361-382, 1964. 